\title{
PAPER
}

\section{Comparison between the lumbar infusion and CSF tap tests to predict outcome after shunt surgery in suspected normal pressure hydrocephalus}

\author{
B Kahlon, G Sundbärg, S Rehncrona
}

J Neurol Neurosurg Psychiatry 2002;73:721-726

See end of article for authors' affiliations

.......................

Correspondence to: Dr S Rehncrona,

Department of

Neurosurgery, University

Hospital, S-221 85 Lund,

Sweden;

stig.rehncrona@neurokir.lu.se

Received

14 December 2001

In revised form

6 June 2002

Accepted

5 September 2002
Objective: To compare the lumbar infusion test and the cerebrospinal fluid (CSF) tap test for predicting the outcome of shunt surgery in patients with suspected normal pressure hydrocephalus.

Methods: 68 patients with suspected normal pressure hydrocephalus were studied. The absence of preceding history indicated idiopathic disease in $75 \%$ of these. All patients were assessed twice with walking and psychometric tests before lumbar infusion test and tap test assessments. The lumbar infusion test was done using a constant infusion rate $(0.80 \mathrm{ml} / \mathrm{min})$ and regarded as positive if the steady state CSF plateau pressure reached levels of $>22 \mathrm{~mm} \mathrm{Hg}$ (resistance to outflow > $14 \mathrm{~mm} \mathrm{Hg} / \mathrm{ml} / \mathrm{min}$ ). The tap test was regarded as positive if two or more of four different test items improved after CSF removal. As the variability in baseline test results was large, the better of two evaluations was used in comparisons with the results after CSF removal, as well as to evaluate the outcome after shunt surgery. Only patients with a positive lumbar infusion test or a positive tap test had surgery.

Results: The results of the CSF tap test and the lumbar infusion test agreed in only $45 \%$ of the patients. Of the total cohort, 47 (69\%) had positive test results and were operated on; $45(96 \%)$ of these reported subjective improvement, and postoperative assessments verified the improvements in 38 $(81 \%)$. Improvements were highly significant in walking, memory, and reaction time tests $(p<0.001)$. Most of the patients improved by surgery $(84 \%)$ were selected by a positive lumbar infusion test, and only $42 \%$ by a positive tap test. Positive predictive values were $80 \%$ for lumbar infusion test and $94 \%$ for tap test. The false negative predictions in the operated group were much higher $(58 \%)$ with the tap test than with the lumbar infusion test (16\%).

Conclusions: Both the lumbar infusion test and the tap test can predict a positive outcome of shunt operations in unselected patients with suspected normal pressure hydrocephalus. The two tests are complementary and should be used together for optimal patient selection.
$\mathrm{N}$ ormal pressure hydrocephalus was first described by Hakim and Adams, ${ }^{1-3}$ as a clinical syndrome with the classical symptom triad of dementia, gait disturbance, and urinary incontinence combined with widening of the cerebral ventricles, but without overt symptoms or signs of raised intracranial pressure. It is generally assumed that the underlying pathophysiological mechanism is an insufficient capacity to absorb cerebrospinal fluid (CSF), but the exact mechanism of the development of the clinical symptoms is not known. ${ }^{1-8}$ The symptoms are potentially reversible, and diversion of CSF by either a ventriculovenous or a ventriculoperitoneal shunt is often successful, ${ }^{1-3}{ }^{9-11}$ provided a correct diagnosis has been made. However, similar clinical symptoms may also occur in other disorders that cause enlargement of the ventricles and thus mimick normal pressure hydrocephalus.. ${ }^{12-15}$ In patients with a recent history of subarachnoid haemorrhage or bacterial meningitis causing a disturbance of CSF absorption, both the diagnosis and the need for shunt surgery may be obvious. ${ }^{16}$ However, it can be difficult to predict the effect of a shunt procedure if a long time has passed, or in the absence of a typical preceding history (that is, idiopathic normal pressure hydrocephalus). Even though the surgical procedure is technically easy there are risks of complications, both short term and long term. ${ }^{11}{ }^{17}$ Thus methods for dynamic measurements of CSF circulation as well as clinical tests have been used to predict the outcome of a shunt procedure.

The most widely used methods involve evaluation of CSF outflow based upon the original lumbar infusion test described by Katzman and Hussey ${ }^{18-23}$ and the standardised CSF tap test introduced by Wikkelsö et al. ${ }^{24} 25$ Our department has used one or other of these methods for several years to select patients assumed to have normal pressure hydrocephalus for shunt surgery. In this prospective study we compared the efficacy of the lumbar infusion test and the CSF tap test in predicting the outcome of shunt operations in an unselected consecutive series of patients.

\section{METHODS \\ Patients}

Eighty one patients with assumed normal pressure hydrocephalus who were referred to the department of neurosurgery, University Hospital in Lund, during the years 1996 to 2000 were included in the study. All patients suffered from either gait disturbance or cognitive dysfunction alone, or from both symptoms combined, or from one or both of them combined with urinary incontinence. Symptom duration was less than eight years. Computed tomography (CT) or magnetic resonance imaging (MRI) showed widening of the ventricular system relative to the age matched ventricular index, as evaluated by a neuroradiologist. A lumbar infusion test and a tap test were done in all patients. The patients and relatives were thoroughly informed and gave their consent.

\section{Procedures}

Lumbar infusion test

The lumbar infusion test was done using a modification of the original method described by Katzman and Hussey. ${ }^{18}{ }^{19}$ With the patient in the lateral recumbent position, two cannulas (diameter $0.9 \mathrm{~mm}$ ) were inserted in the lower lumbar region (L3-4 or L4-5). One of these was connected to a closed pressure 
Table 1 Demographic data and symptoms

\begin{tabular}{|c|c|c|c|c|c|c|c|}
\hline & \multirow[b]{2}{*}{$\mathrm{n}$} & \multirow[b]{2}{*}{ Age (years) } & \multirow[b]{2}{*}{ Male } & \multirow[b]{2}{*}{ Female } & \multicolumn{3}{|l|}{ Symptoms } \\
\hline & & & & & Gait & Memory & Incontinence \\
\hline Total & 68 & $72(9)$ & $29(43 \%)$ & 39 (57\%) & 62 (91\%) & $52(76 \%)$ & 41 (60\%) \\
\hline Not operated & 21 (31\%) & 68 (11) & $10(48 \%)$ & 11 (52\%) & $18(86 \%)$ & 15 (71\%) & $10(48 \%)$ \\
\hline Operated & 47 (69\%) & 73 (7) & 19 (40\%) & $28(60 \%)$ & 44 (94\%) & 37 (79\%) & 31 (66\%) \\
\hline LIT pos & 40 (59\%) & 73 (7) & 17 (43\%) & 23 (57\%) & 37 (93\%) & 33 (83\%) & 27 (68\%) \\
\hline TT pos & $17(25 \%)$ & $72(8)$ & $8(47 \%)$ & $9(53 \%)$ & $17(100 \%)$ & $11(65 \%)$ & $11(65 \%)$ \\
\hline LIT pos, TT pos & $10(15 \%)$ & 72 (10) & $6(60 \%)$ & $4(40 \%)$ & $10(100 \%)$ & $7(70 \%)$ & $7(70 \%)$ \\
\hline LIT neg, TT pos & $7(10 \%)$ & $73(6)$ & $2(29 \%)$ & $5(71 \%)$ & $7(100 \%)$ & $4(57 \%)$ & $4(57 \%)$ \\
\hline LIT pos, TT neg & $30(44 \%)$ & $74(6)$ & $11(37 \%)$ & $19(63 \%)$ & $27(90 \%)$ & $26(87 \%)$ & $20(67 \%)$ \\
\hline
\end{tabular}

recording device (Serogor 110, Goerz) and the other to an infusion pump (Top syringe pump 5100). The initial steady state CSF pressure was recorded for at least five minutes before starting an infusion of Ringer solution ( $\mathrm{NaCl} 8.6 \mathrm{~g} / \mathrm{l}, \mathrm{KCl} 0.3 \mathrm{~g} / \mathrm{l}, \mathrm{CaCl}$ $0.33 \mathrm{~g} / \mathrm{l} ; 290 \mathrm{mosm} / \mathrm{kg}$ ). The constant infusion rate was 0.80 $\mathrm{ml} / \mathrm{min}$. The CSF pressure was recorded continuously during a period of at least 45 minutes, to establish a steady state pressure plateau representing the pressure level at which absorption balanced infusion. A plateau pressure level exceeding $22 \mathrm{~mm}$ $\mathrm{Hg}^{18}{ }^{19}$ was considered pathological (a positive test result). Alternatively, if the CSF pressure increased steadily to greater than 40 $\mathrm{mm} \mathrm{Hg}$ without a plateau (one patient) the infusion was stopped and the test was regarded as positive. After completion of the infusion test the lumbar puncture cannulas were left in place until the CSF pressure had returned to the initial preinfusion resting value and had been stable for 10 minutes.

\section{CSF tap test}

The CSF tap test-which was carried out according to Wikkelsö et al, ${ }^{24}$ with minor modifications-was done directly after the lumbar infusion test and involved assessing the effect on a series of functional tests of removing $50 \mathrm{ml}$ of CSF through one of the cannulas used for the infusion test. We had previously obtained baseline data for walking ability and psychometric tests (reaction time test, ${ }^{25}$ memory test, ${ }^{26}$ and identical forms test ${ }^{27}$ ) on two separate occasions at the same time of day, on the first and second days after admission. After CSF removal and a rest period of one to three hours, these tests were repeated for comparison with the baseline data. The tests were done at the same time of day as the baseline tests.

The test battery included the following:

- Walking test ${ }^{24}{ }^{25}$-The patient was asked to walk a distance of $18 \mathrm{~m}$ as fast as possible. The test was repeated three times and the number of steps as well as the performance time was recorded. The average of the three attempts was calculated and used as the test result.

- Reaction time ${ }^{24}{ }^{25}$-The patient was asked to press the button on the mouse of a computer as quickly as possible in response to an auditory signal (a bleep) or a visual signal (a red dot) delivered by the computer. The response time (ms) was recorded. The test was performed in three cycles. Each cycle delivered five signals with randomly varied resting times (three to seven seconds) in between. The average reaction time from three attempts formed the test result.

- Memory test-Bingley's charts were used. ${ }^{26}$ The patient was shown two of the charts for 30 seconds and was then asked to recall the figures from the charts. Every correctly remembered figure earned one point and the average score was calculated as the test result.

- Identical forms ${ }^{27}$-The patient was asked to perceive a figure and then recall it among five similar figures, only one being correct. Each correct answer scored one point while a wrong answer received a penalty of 0.25 points. The test duration time was six minutes. The test result was calculated as the sum of all correct answers minus the wrong answers.
The results obtained after CSF removal were compared with the best of the results from the two baseline tests. At least a 5\% improvement in walking and reaction time and at least a 25\% improvement in memory and identical forms tests, respectively, were required for the individual test to be classed as improved. ${ }^{25}$ The tap test was considered positive if two or more of the four different items improved after CSF removal. ${ }^{25}$

\section{Surgery}

Surgery was undertaken if either the lumbar infusion test or the tap test or both tests were positive. The patients received a ventriculoperitoneal or a ventriculovenous shunt, using an adjustable valve (Medos, Codman). Postoperatively, the opening pressures of the valves were individually adjusted if necessary to the optimal level for each patient $\left(8-17 \mathrm{~mm} \mathrm{H}_{2} \mathrm{O}\right.$ ).

If both tests were negative, surgery was not undertaken.

\section{Evaluation of outcome}

All patients, both operated and non-operated, were evaluated at a follow up visit after (mean (SD)) 6.0 (4.5) months (operated, 6.0 (5.0) months; non-operated 6.0 (4.2) months) using the same test battery as at baseline. In accordance with the tap test criteria, the patients were considered objectively improved if two or more of the test items showed improvement (>5\% for the walking test and the reaction time test; $>25 \%$ for the memory and identical forms tests) compared with the better of the two baseline results. Patients and relatives were also asked for their subjective opinion as to whether or not there had been an improvement.

\section{Statistics}

Descriptive statistics are given as mean (SD). Differences were compared statistically using the Wilcoxon matched pairs signed ranks test. Probability (p) values below 0.05 were considered statistically significant. Four patients were not able to perform all the different items included in the test battery on one or other occasion. These were excluded from statistical analyses and described separately in tables 4 and 5 .

\section{RESULTS}

\section{Patients, demographic data, and symptoms}

In all, 81 patients were eligible for inclusion in the study, but 13 had to be excluded, as follows. Eight were lost to follow up because of refusals (3), intercurrent disease (1), moved a long way away (1), or missed attending (3); all these patients had a negative lumbar infusion test and a negative tap test and therefore did not fulfil the criteria for surgery. Three further patients refused surgery (two with a positive lumbar infusion test and a negative tap test, one patient with a negative lumbar infusion test and a positive tap test). Finally, two patients were excluded because of lost data. Thus 68 patients remained in the study and all the results refer to these patients. Their demographic data and symptoms are summarised in table 1 .

The study included 29 men and 39 women, mean age 72 (9) years (median 74 years, range 38 to 84 ). Forty seven of the patients $(69 \%)$ met the criteria for surgery and were operated 
Table 2 Baseline test results on day 1 and day 2

\begin{tabular}{|c|c|c|c|c|c|c|c|c|}
\hline & \multirow[b]{2}{*}{ Test day 1} & \multirow[b]{2}{*}{ Test day 2} & \multirow{2}{*}{$\begin{array}{l}\text { Difference } \\
\text { between day } 1 \\
\text { and day } 2(\%)\end{array}$} & \multicolumn{2}{|c|}{$\begin{array}{l}\text { Difference between day } \\
1 \text { and day } 2\end{array}$} & \multirow{2}{*}{$\begin{array}{l}\text { Best result } \\
\text { day } 1\end{array}$} & \multirow{2}{*}{$\begin{array}{l}\text { Best result } \\
\text { day } 2\end{array}$} & \multirow{2}{*}{$\begin{array}{l}\text { Similar } \\
\text { result }\end{array}$} \\
\hline & & & & $>5 \% *$ & $>25 \% *$ & & & \\
\hline Walking test (No of steps) & $46(30)$ & 46 (29) & $8(8)$ & $34(50 \%)$ & & $20(29 \%)$ & $38(56 \%)$ & $10(15 \%)$ \\
\hline Walking test (time) (s) & $30(23)$ & $29(22)$ & $12(10)$ & 42 (62\%) & & $19(28 \%)$ & $41(60 \%)$ & $8(12 \%)$ \\
\hline Reaction time (ms) & $653(1070)$ & $614(1008)$ & 17 (13) & 47 (70\%) & & 22 (33\%) & $41(60 \%)$ & $5(7 \%)$ \\
\hline Memory (No of correct answers) & $3.2(1.9)$ & $3.3(1.9)$ & 40 (50) & & $28(41 \%)$ & $24(35 \%)$ & 31 (46\%) & $13(19 \%)$ \\
\hline $\begin{array}{l}\text { Identical forms test (No of correct } \\
\text { answers) }\end{array}$ & $16(11)$ & $19(13)$ & 37 (40) & & $27(40 \%)$ & 13 (19\%) & $45(66 \%)$ & $10(15 \%)$ \\
\hline
\end{tabular}

on, while 21 (31\%) did not. There were no obvious differences in demographic data between these two groups.

Eight patients had an earlier history of spontaneous intracranial haemorrhage (more than five years before, including one patient with subarachnoid haemorrhage). Four of these patients met the criteria for operation. One of two patients with an earlier history of central nervous system infection ( $>5$ years before) met the criteria for shunt surgery. Three of five patients with earlier history of severe head trauma ( $>5$ years before) met the criteria for a shunt procedure, while neither of two patients operated on earlier for benign intracranial tumours met the criteria. In the majority of cases (75\%) there was no evidence of earlier neurological disease to explain the development of normal pressure hydrocephalus. The incidence of cardiovascular disease was high (62\%).

Disturbance of gait was the most common preoperative symptom (91\%), while fewer patients suffered from cognitive impairment $(76 \%)$ or incontinence $(60 \%)$. In most patients, different combinations of symptoms were found. Of 31 patients who had all three symptoms of the classical triad, 25 $(81 \%)$ had either a positive lumbar infusion test, a positive tap test, or both, while of 12 patients with one symptom, seven had a positive test result ( $58 \%$ ), and of 25 with two symptoms, 15 had a positive result $(60 \%)$.

\section{Complications and assessment of shunt function}

There were no complications or side effects related to the lumbar infusion test or the tap test. In three patients the shunting procedure was complicated by a subdural haematoma: in one of these (in whom both the lumbar infusion test and the tap test were positive) the haematoma was managed surgically; in the other two (lumbar infusion test positive; tap test negative) the haematomas did not require evacuation and were absorbed spontaneously. One patient had a postoperative shunt infection with meningitis and was treated with antibiotics and removal of the shunt. After a few months a new shunt was inserted. All complications had resolved before the follow up assessment.

All operated patients who did not show objective improvement at the follow up evaluation $(\mathrm{n}=9)$ had a plain skull $x$ ray, CT of the head, and a repeat lumbar infusion test. In all cases, shunt placement, continuity, and function were found to be adequate.

\section{Variability of the baseline tests}

In order to study and compensate for spontaneous variations in the patients' ability to perform the different tests, we used the mean values of three measurements for the walking and reaction time evaluations, and repeated all tests at a similar time of the day on two different days before CSF removal. Table 2 gives the results of the two baseline tests. The spontaneous variations in the results on day 1 and day 2 were quite large, though the group mean values were similar. Thus there was a difference of more than $5 \%$ in the walking and reaction time evaluations in $50-70 \%$ of the patients, while around $40 \%$ of the patients showed more than $25 \%$ difference in the identical forms and memory tests. Similar test results were obtained on day 1 and day 2 in $7-20 \%$ of the patients, but in the majority $(50-65 \%)$ the results were better on the second assessment.

\section{Tap test and lumbar infusion test $v$ outcome}

In 31 patients $(45 \%)$ the tap test and the lumbar infusion test showed a similar result - that is, both tests were either positive or negative. In 37 patients (55\%) the results diverged. Table 3 summarises the results of the tap test and the lumbar infusion test and relates them to the clinical outcome. Of 21 patients not operated on (because both the tap test and the lumbar infusion test were negative), five (24\%) were objectively improved at follow up and four also reported subjective improvement. Of these five patients, two had an earlier history of traumatic intracranial haemorrhage and one of aneurysmal subarachnoid haemorrhage, while two had no earlier history. Despite these individual improvements in the non-operated group, none of the four postoperative tests showed any statistically significant change compared with baseline (table 4).

Forty seven patients fulfilled the criteria for surgery and underwent the shunting procedure. Thirty eight $(81 \%)$ of these patients showed an objectively verified improvement and 45 (96\%) reported a subjective improvement (table 3). Of the 38

Table 3 Number of patients improved at follow up related to the results of lumbar infusion tests and cerebrospinal fluid tap tests

\begin{tabular}{llll}
\hline & n (\%) of total cohort & Objectively improved & Subjectively improved \\
\hline Not operated on $\dagger$ & $21(31 \%)$ & $5(24 \%)$ & $4(19 \%)$ \\
Operated on $\neq$ & $47(69 \%)$ & $38(81 \%)$ & $45(96 \%)$ \\
LIT pos & $40(59 \%)$ & $32(80 \%)$ & $39(98 \%)$ \\
TT pos & $17(25 \%)$ & $16(94 \%)$ & $16(94 \%)$ \\
IIT pos/TT neg & $30(44 \%)$ & $22(73 \%)$ & $29(97 \%)$ \\
LIT neg/TT pos & $7(10 \%)$ & $6(86 \%)$ & $6(86 \%)$ \\
LIT pos/TT pos & $10(15 \%)$ & $10(100 \%)$ & $10(100 \%)$ \\
\hline
\end{tabular}

$\dagger$ Neither LIT nor TT was positive.

†Either LIT or TT or both tests were positive.

Objective improvement was according to the tap test criteria (see Methods); subjective improvement was according to patients and relatives.

LIT, lumbar infusion test; neg, negative; pos, positive; TT, cerebrospinal fluid tap test. 
Table 4 Statistical analysis of outcome in functional tests as compared with baseline' in shunt operated and non-operated groups

\begin{tabular}{|c|c|c|c|}
\hline & & $\begin{array}{l}\text { Operated } \\
(n=47)\end{array}$ & $\begin{array}{l}\text { Not operated } \\
(n=21)\end{array}$ \\
\hline $\begin{array}{l}\text { Walking test } \\
\text { (number of steps) }\end{array}$ & $\begin{array}{l}\text { Baseline } \\
\text { Follow up } \\
\text { Mean difference }\end{array}$ & $\begin{array}{l}47(28)^{2} \\
40(31)^{* * *} \\
7(31)\end{array}$ & $\begin{array}{l}35(23) \\
39(24) \\
-4(9)^{3}\end{array}$ \\
\hline $\begin{array}{l}\text { Walking test } \\
\text { (time) (s) }\end{array}$ & $\begin{array}{l}\text { Baseline } \\
\text { Follow up } \\
\text { Mean difference }\end{array}$ & $\begin{array}{l}29(23)^{2} \\
24(25)^{* * *} \\
5(26)\end{array}$ & $\begin{array}{l}22(16) \\
25(19) \\
-3(9)\end{array}$ \\
\hline $\begin{array}{l}\text { Memory (number } \\
\text { of correct } \\
\text { answers) }\end{array}$ & $\begin{array}{l}\text { Baseline } \\
\text { Follow up } \\
\text { Mean difference }\end{array}$ & $\begin{array}{l}3.6(1.8) \\
4.4(2.0)^{* * *} \\
0.7(1.2)\end{array}$ & $\begin{array}{l}3.5(2.4) \\
3.4(2.7) \\
-0.1(1.3)\end{array}$ \\
\hline $\begin{array}{l}\text { Reaction time } \\
\text { (ms) }\end{array}$ & $\begin{array}{l}\text { Baseline } \\
\text { Follow up } \\
\text { Mean difference }\end{array}$ & $\begin{array}{l}427(333)^{2} \\
320(182)^{* * *} \\
107(218)\end{array}$ & $\begin{array}{l}921(1611) \\
512(467) \\
410(1303)\end{array}$ \\
\hline $\begin{array}{l}\text { Identical forms } \\
\text { test (number of } \\
\text { correct answers) }\end{array}$ & $\begin{array}{l}\text { Baseline } \\
\text { Follow up } \\
\text { Mean difference }\end{array}$ & $\begin{array}{l}19(12) \\
21(13) \\
2(8)\end{array}$ & $\begin{array}{l}17(15) \\
17(19) \\
0(7)\end{array}$ \\
\hline
\end{tabular}

Values are mean (SD).

$* * * p<0.001 v$ baseline; no other differences significant.

'Baseline values refer to the best of two results.

${ }^{2}$ Four patients unable to perform all the tests were excluded from the analyses (see table 5).

${ }^{3} \mathrm{~A}$ minus sign for difference indicates a change for the worse.

patients with objective improvement, $32(84 \%)$ had a positive lumbar infusion test but only $16(42 \%)$ a positive tap test. Only one of the nine patients who was not improved had a negative lumbar infusion test, while eight had a negative tap test.

In the operated group, walking, memory and reaction time tests showed highly significant improvements $(p<0.001)$, while the identical forms test did not improve significantly (table 4). Forty patients with a positive lumbar infusion test (59\%) had significant improvements in walking, memory, and reaction time tests (table 5 ). In 17 patients (25\%) with a positive tap test, memory, reaction time, and identical forms tests were significantly improved at the follow up evaluation, but an apparent improvement in the walking tests did not reach statistical significance (table 5). Only 10 patients were positive for both the lumbar infusion and the CSF tap tests, and all these were both objectively and subjectively improved postoperatively (table 3). In this group of patients the improvement was statistically significant for memory and reaction time tests (table 5).

In two groups of patients there was a discrepancy between the results of the lumbar infusion test and the tap test (table 3 ). In 30 patients a positive lumbar infusion test was an indication for shunt surgery, but the tap test was negative, while seven patients had surgery because of a positive tap test but had a negative lumbar infusion test. The improvement in walking, reaction time, and memory tests after surgery was significant in the first group but not in the second (table 5).

\section{Degree of postoperative improvement}

Figure 1 shows the clinical outcome in the operated patients with respect to their degree of improvement in the different tests. In the majority of patients walking improved by more than $20 \%$ and reaction time by more than $10 \%$. In $10 \%$ of the patients these tests were improved by more than $50 \%$. Fewer patients showed improvements in cognitive function above the cut off levels. Thus $50 \%$ of the operated patients improved by more than $25 \%$ in memory but only $35 \%$ improved by more than $25 \%$ in the identical forms test. Ten per cent showed more than $100 \%$ improvement in these tests. The pattern was similar for patients with a positive lumbar infusion test and patients with a positive tap test except for the identical forms test, which improved more in patients with a positive tap test.

\section{DISCUSSION}

Our aim in this prospective study was to establish how well the results of the lumbar infusion test and the tap test agree with each other and with the outcome after shunt treatment for suspected normal pressure hydrocephalus. To our knowledge this is the first time these two methods have been directly compared in the same group of patients.

The results show that both tests can predict a positive outcome after surgery, but there was agreement between the test results in only $45 \%$ of the patients. Before discussing the clinical implications of the findings we will consider some methodological aspects.

\section{Methodological considerations}

Both the tap test and the lumbar infusion test require lumbar puncture, and even though this can be done with small diameter needles it is difficult to exclude the possibility that repeated lumbar punctures within a limited time period may influence the test results. Thus if the tap test is performed first, a leak from the puncture may influence the result of a lumbar infusion test, at least for some weeks afterwards. On the other

Table 5 Statistical analysis of outcome in functional tests after shunt operation compared with baseline in patients positive for lumbar infusion and CSF tap tests

\begin{tabular}{|c|c|c|c|c|c|c|}
\hline & & LIT positive $(n=40)$ & $\begin{array}{l}\text { Th positive } \\
(\mathrm{n}=17)\end{array}$ & $\begin{array}{l}\text { LIT and TT positive } \\
(n=10)\end{array}$ & $\begin{array}{l}\text { LIT positive/TT } \\
\text { negative }(n=30)\end{array}$ & $\begin{array}{l}\text { LIT negative/TT } \\
\text { positive }(n=7)\end{array}$ \\
\hline \multirow{2}{*}{$\begin{array}{l}\text { Walking test (number of } \\
\text { steps) }\end{array}$} & Baseline' $^{\prime}$ & $48(29)^{2}$ & $44(21)$ & $47(21)$ & $49(32)^{2}$ & $40(24)$ \\
\hline & Follow up & $41(33)^{* * *}$ & $36(19)$ & $37(20)$ & $42(37)^{* * *}$ & 34 (18) \\
\hline \multirow[t]{2}{*}{ Walking test (time) (s) } & Baseline & $29(24)^{2}$ & $26(14)$ & $26(11)$ & $31(27)^{2}$ & 27 (19) \\
\hline & Follow up & $25(27)^{* * *}$ & $22(16)$ & $22(18)$ & $26(30) * * *$ & $21(14)$ \\
\hline \multirow{2}{*}{$\begin{array}{l}\text { Memory (number of correct } \\
\text { answers) }\end{array}$} & Baseline & $3.7(1.8)$ & 3.7 (1.9) & 3.8 (1.7) & $3.6(1.9)$ & $3.6(2.2)$ \\
\hline & Follow up & $4.4(2.1)^{* * *}$ & $4.6(1.3)^{*}$ & $4.9(1.5)^{* *}$ & $4.2(2.3)^{* *}$ & $4.1(1.1)$ \\
\hline \multirow[t]{2}{*}{ Reaction time (ms) } & Baseline & $377(218)^{2}$ & $506(443)$ & $374(175)$ & $378(235)^{2}$ & 693 (639) \\
\hline & Follow up & $298(151)^{* *}$ & $351(205)^{* *}$ & $294(97)^{*}$ & $300(168)^{*}$ & $433(290)$ \\
\hline \multirow{2}{*}{$\begin{array}{l}\text { Identical forms test (number } \\
\text { of correct answers) }\end{array}$} & Baseline & $19.3(12.3)$ & $17.1(12.0)$ & $17.6(11.0)$ & $19.8(12.8)$ & $16.5(14.0)$ \\
\hline & Follow up & $20.3(12.4)$ & $23.6(13.0)^{* *}$ & $23.6(7.4)$ & $19.2(13.5)$ & 24.0 (19.0) \\
\hline
\end{tabular}

Values are mean (SD).

${ }^{*} \mathrm{p}<0.05 ;{ }^{* *} \mathrm{p}<0.01 ;{ }^{* * *} \mathrm{p}<0.001 v$ baseline (Wilcoxon matched pairs signed ranks test); no other difference significant.

'Baseline values refer to the best of two results.

${ }^{2}$ One patient was unable to walk and one was unable to walk or to perform the reaction time test at baseline, but both were fully able to perform at follow up. Two patients did not manage the reaction time test at follow up. These patients were all excluded from the statistical analyses of those particular tests. LIT, lumbar infusion test; TT, cerebrospinal fluid tap test. 


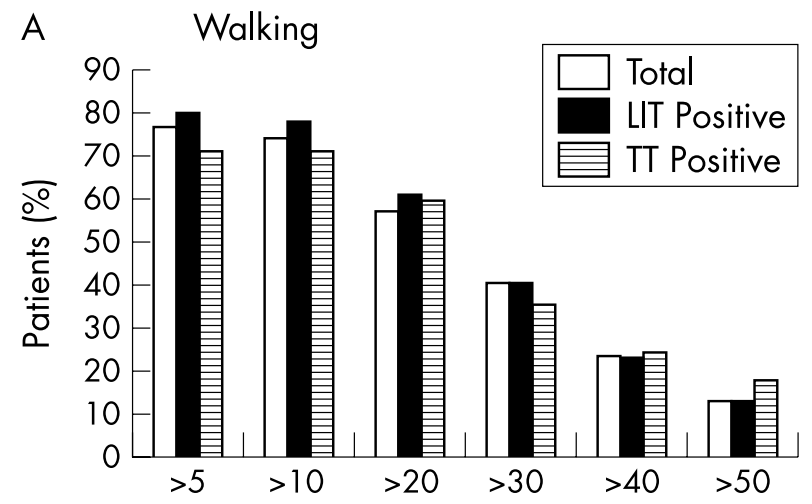

B

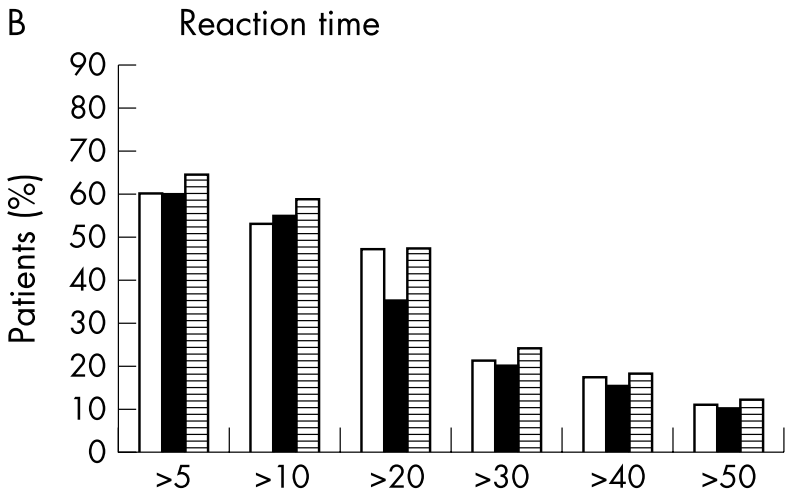

C

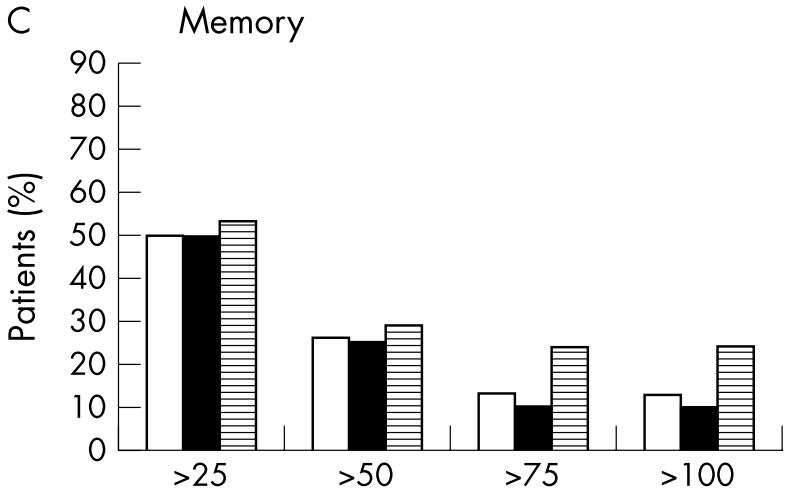

D

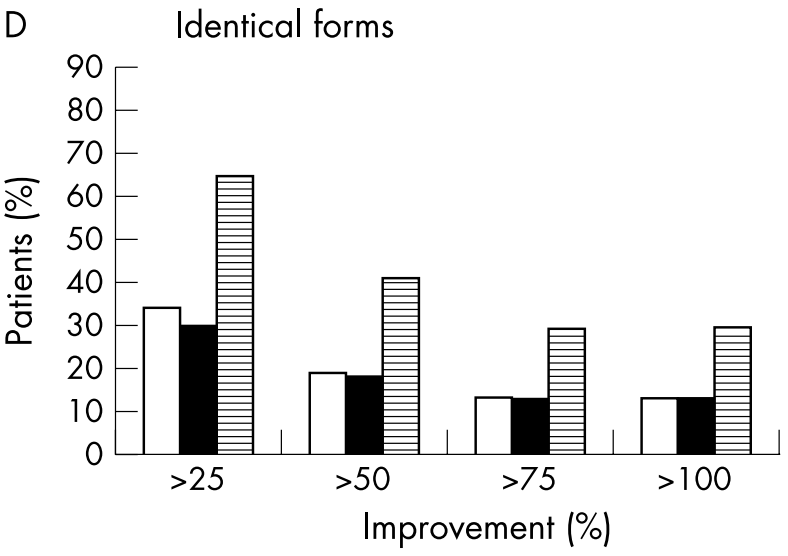

Figure 1 Degree of improvement (per cent) in walking time, reaction time, memory, and identical forms tests after shunt operation in patients with normal pressure hydrocephalus, as diagnosed using the lumbar infusion test (LIT) or the cerebrospinal fluid tap test (TT).

Total $=$ all operated patients . hand, a leak after a lumbar infusion test could influence the result of baseline test data before CSF drainage in the tap test. To circumvent these difficulties we chose to perform both tests on the same day, using the same lumbar puncture. We have earlier observed that patients may improve for a time after a lumbar infusion test and have interpreted this as being a possible effect of leakage of CSF after the lumbar puncture. If so, this effect is similar to the effect measured by the tap test and should not, therefore, influence the result a tap test performed directly after the lumbar infusion test using the same lumbar puncture.

\section{Lumbar infusion test}

For the lumbar infusion test we followed the routines of our department and defined the level of pathological CSF absorptive capacity in accordance with Katzman and Hussey. ${ }^{18}{ }^{19}$ A pressure of $22 \mathrm{~mm} \mathrm{Hg}$ was regarded as the cut off level above which the mean steady state plateau during the infusion was considered pathological. As the initial steady state level of resting pressure was 11 (3) $\mathrm{mm} \mathrm{Hg}(\mathrm{n}=68)$ and the constant infusion rate was $0.80 \mathrm{ml} / \mathrm{min}$, this plateau level corresponds to a CSF outflow resistance of about $14 \mathrm{~mm} \mathrm{Hg} / \mathrm{ml} / \mathrm{min}$ or an outflow conductance of about $0.073 \mathrm{ml} / \mathrm{min} / \mathrm{mm} \mathrm{Hg} .{ }^{21}{ }^{23} \mathrm{How}-$ ever, calculations of outflow resistance or conductance do not take into account the possibility that the patient's own production of CSF may vary at different intracranial pressure levels, and that the initial pressure level (before the start of the infusion) may vary for reasons unrelated to CSF hydrodynamics. Lumbar infusion test pressure curves need to be scrutinised with respect to their initial levels and amplitudes compared with the outcome after shunting.

\section{CSF tap test}

The CSF tap test has the advantage of being simple to perform without any specialised equipment. Drawbacks include the fact that the testing procedure needs active cooperation from the patients, and that unrelated diseases or deficits may interfere with the result. This is at least partly compensated for by using four different test items, with the requirement that improvement in only two of them is needed for a positive test result. More importantly, there may be spontaneous variation in the patient's ability to perform the tests, and the validity of the stipulated cut off levels for significant improvement ${ }^{24} 25$ may be challenged. In fact our results confirmed a high spontaneous variation in baseline test results when repeated in the same patient. Most patients performed better when the baseline tests were repeated on the second day, indicating some learning effect. Because we anticipated the possibility of spontaneous variation, we always used the better of the two baseline tests in comparisons with the result after CSF removal, as well as for evaluating the outcome at follow up. As the improvement in the test result after CSF removal was greater than the difference between the two baseline tests in $85 \%$ of all assessments in patients with a positive tap test, we assume that the improvement was caused by tapping off CSF and was not merely a reflection of spontaneous variation in the patients' ability to perform the tests.

In earlier studies of normal pressure hydrocephalus, using standardised tap test criteria, the baseline tests were performed only once before removal of CSF. ${ }^{242829}$ The present results indicate that the baseline assessments should be repeated on different occasions and the best of at least two test procedures should be used to compare with the result after CSF removal.

The validity of the levels for significant improvement in the tap test is open to discussion in view of our results. Of the 38 patients improved after shunting, the tap test predicted a positive result only in $42 \%$. A decrease in the cut off levels would have tended to increase the numbers of patients selected for surgery, but this seems inadvisable in view of the fact that they are already in the range of spontaneous variation. By the same token, an increase in the cut off levels 
would tend to further (and falsely) decrease the number of patients selected for surgery.

\section{Evaluation of outcome}

In the present cohort, we used the same test battery and principles that are included in the tap test protocol to establish improvement objectively. The practical value of a 5\% improvement in the walking and reaction time tests and a $25 \%$ improvement in the psychometric is unclear. However, the patients' (and relatives') subjective impression of the clinical outcome was in good agreement with the test results. The subjective evaluations showed improvement in a greater number of patients than the objective tests, which may reflect the fact that more than one functional test had to be improved to classify the patient as objectively improved; however, it may also include a placebo effect.

\section{Prediction of outcome}

Both the tap test and the lumbar infusion test were shown to predict a positive outcome of shunt surgery in patients with suspected normal pressure hydrocephalus. As we followed the departmental routine of not basing the decision for surgery on clinical symptoms and ventricular widening alone, patients with negative results in both the lumbar infusion test and the tap test were not operated on. Thus the total number of false negative values is unknown and the exact values for sensitivity and specificity cannot be calculated. The positive predictive value was high for the tap test (94\%), but 22 patients $(58 \%)$ with improvement after shunt operations would have been missed if this test had been used alone. The positive predictive value of lumbar infusion test was $80 \%$ and if used alone the test would only have missed six of the patients who improved after surgery $(16 \%)$. On the other hand eight patients were unnecessarily operated on because of a positive lumbar infusion test, but only one with a positive tap test. These data indicate that the lumbar infusion test is the more sensitive test and the tap test is the more specific. Only in the small group of patients in whom both tests were positive did every patient improve after shunting. However, 28 patients $(74 \%)$ with postoperative improvement would have been missed if both tests were required to be positive before considering surgical treatment. Taken together, the data indicate that the tap test and the lumbar infusion test are complementary diagnostic tools. This is not surprising in view of the fact that they assess different qualities.

\section{Conclusions}

In a patient cohort with clinically suspected normal pressure hydrocephalus but otherwise unselected, the greatest number of patients $(>80 \%)$ with improvement after shunt surgery were selected by a positive lumbar infusion test, while fewer $(<50 \%)$ were selected by a positive CSF tap test. There was only partial agreement between the two tests and they complement each other. We therefore suggest that both tests are included in a preoperative evaluation programme, and one or both should be positive before recommending surgery. If facilities are available, both tests can be performed at the same occasion.

As the positive predictive value of the tap test is greater than that of the lumbar infusion test, surgery may be based on a positive tap test alone. If negative, however, the tap test must be complemented by a lumbar infusion test, as the proportion of missed patients with false negative results was much higher with the tap test. The high level of spontaneous variability in the test results at baseline means that they must be repeated before making comparisons with the results after CSF removal.

\section{ACKNOWLEDGEMENTS}

We acknowledge the Medical Faculty, University in Lund for financial support. Birgitta Kahlmeter, Birgitta Ekelund, and Maria Nilsson provided excellent help with the CSF tap tests and Sven Söderström provided expert technical assistance with the lumbar infusion tests. PärOla Bendahl helped with statistical calculations.

\section{Authors' affiliations}

B Kahlon, G Sundbärg, S Rehncrona, Department of Neurosurgery,

University Hospital, Lund, Sweden

Competing interests: none declared

\section{REFERENCES}

1 Hakim S, Adams RD. The special clinical problem of symptomatic hydrocephalus with normal cerebrospinal fluid pressure. Observations on cerebrospinal fluid hydrodynamics. J Neurol Sci 1965;2:307-27.

2 Adams RD, Fisher CM, Hakim S, et al. Symptomatic occult hydrocephalus with "normal" cerebrospinal fluid pressure. A treatable syndrome. N Engl J Med 1966;273:117-26.

3 Adams RD. Further observations on normal pressure hydrocephalus. Proc R Soc Med 1966;59:1 135-40.

4 Conner ES, Foley L, Black PM, et al. Experimental normal-pressure hydrocephalus is accompanied by increased transmantle pressure. $J$ Neurosurg 1984:61:322-7.

5 Di Rocco C, Di Trapani G, Pettorossi VE, et al. On the pathology of experimental hydrocephalus induced by artificial increase in endoventricular CSF pulse pressure. Childs Brain 1979;5:81-95.

6 Matsuda M, Nakasu S, Nakazawa T, et al. Cerebral hemodynamics in patients with normal pressure hydrocephalus: correlation between cerebral circulation time and dementia. Surg Neurol 1990:34:396-401.

7 Hayashi H, Tanaka K, Naruse H, et al. Changes in dementia after shun surgery for normal pressure hydrocephalus. No To Shinkei 1992;44:429-34. (In Japanese.)

8 Kimura M, Tanaka A, Yoshinaga S. Significance of periventricular hemodynamics in normal pressure hydrocephalus. Neurosurgery 1992;30:701-4; discussion:704-5

9 Ojemann RG, Fisher CM, Adams RD, et al. Further experience with the syndrome of "normal" pressure hydrocephalus. J Neurosurg 1969:31:279-94.

10 Dauch WA, Zimmermann R. Normal pressure hydrocephalus. An evaluation 25 years following the initial description. Fortschr Neurol Psychiatr 1990:58:178-90

11 Larsson A, Wikkelso C, Bilting M, et al. Clinical parameters in 74 consecutive patients shunt operated for normal pressure hydrocephalus. Acta Neurol Scand 1991;84:475-82.

12 Katzman R. Dementias. Postgrad Med 1978;64:119-25.

13 Nadeau SE. Multi-infarct dementia, subcortical dementia, and hydrocephalus. South Med J 1991;84(5 suppl 1):S41-52.

14 Haines A, Katona C. Dementia in old age. Occas Pap R Coll Gen Pract 1992:62-6.

15 Elble RJ, Hughes L, Higgins C. The syndrome of senile gait. J Neurol 1992;239:71-5

16 Sheehan JP, Polin RS, Sheehan JM, et al. Factors associated with hydrocephalus after aneurysmal subarachnoid hemorrhage. Neurosurgery 1999;45: $1120-7$; discussion: 1127-8.

17 Udvarhelyi GB, Wood JH, James AE, et al. Results and complications in 55 shunted patients with normal pressure hydrocephalus. Surg Neurol $1975 ; 3: 271-5$

18 Katzman R, Hussey F. A simple constant-infusion manometric test for measurement of CSF absorption. I. Rationale and method. Neurology 1970;20:534-44

19 Hussey F, Schanzer B, Katzman R. A simple constant-infusion manometric test for measurement of CSF absorption. II. Clinical studies. Neurology 1970;20:665-80.

20 Ekstedt J. CSF hydrodynamic studies in man. 1. Method of constant pressure CSF infusion. J Neurol Neurosurg Psychiatry 1977;40:105-19.

21 Ekstedt J. CSF hydrodynamic studies in man. 2. Normal hydrodynamic variables related to CSF pressure and flow. J Neurol Neurosurg Psychiatry 1978;41:345-53

22 Borgesen SE, Gjerris F, Sorensen SC. The resistance to cerebrospinal fluid absorption in humans. A method of evaluation by lumbo-ventricular perfusion, with particular reference to normal pressure hydrocephalus. Acta Neurol Scand 1978;57:88-96.

23 Borgesen SE. Conductance to outflow of CSF in normal pressure hydrocephalus. Acta Neurochir 1984;71:1-45.

24 Wikkelsö C, Andersson H, Blomstrand C, et al. The clinical effect of lumbar puncture in normal pressure hydrocephalus. J Neurol Neurosurg Psychiatry 1982;45:64-9.

25 Wikkelsö C, Andersson H, Blomstrand C, et al. Normal pressure hydrocephalus. Predictive value of the cerebrospinal fluid tap-test. Acto Neurol Scand 1986;73:566-73.

26 Bingley T. Mental symptoms in temporal lobe epilepsy and tempora lobe gliomas. With special reference to laterality of lesion and the relationship between handedness and brainedness. Acta Psychiatr Neurol Scand 1958;suppl 120:1-43.

27 Thurstone LL. Primary mental abilities. Chicago: The University of Chicago Press, 1943:40-41.

28 Malm J, Kristensen B, Karlsson T, et al. The predictive value of cerebrospinal fluid dynamic tests in patients with the idiopathic adult hydrocephalus syndrome. Arch Neurol 1995;52:783-9.

29 Damasceno BP, Carelli EF, Honorato DC, et al. The predictive value of cerebrospinal fluid tap-test in normal pressure hydrocephalus. Arq Neuropsiquiatr 1997;55:179-85. 